\section{JTET}

http://penerbit.uthm.edu.my/ojs/index.php/jtet ISSN 2229-8932 e-ISSN 2600-7932
Journal of Technical

Education and

Training

\title{
Technical Competencies in Digital Technology towards Industrial Revolution 4.0
}

\author{
Asnidatul Adilah Ismail ${ }^{1}$, Razali Hassan ${ }^{2 *}$ \\ 1,2 Faculty of Technical and Vocational Education, Universiti Tun Hussein Onn Malaysia, Parit Raja, 86400, \\ MALAYSIA
}

DOI: https://doi.org/10.30880/jtet.2019.11.03.008

Received $28^{\text {th }}$ August 2018; Accepted $31^{\text {st }}$ March 2019; Available online $30^{\text {th }}$ September 2019

\begin{abstract}
In the contemporary digitalisation and robotics world, industries are facing what is known as the Industrial Revolution 4.0 (IR4.0). The belief by most experts is that some professions will be replaced by emerging technologies. As such, the education sector is affected as only qualified, highly skilled and educated employees are required. IR4.0 technologies have created new jobs in meeting the needs of the existing market, as such more services and unique products will be introduced. Therefore, this study identifies the technical competency needed by industries towards future industrial revolution for TVET graduates. This study uses qualitative method and has implemented survey method of distributing a set of questionnaires to selected respondents. The study also employs the use of structured interview session with two TVET experts in order to support the findings. Purposive sampling was used to select the respondent, where the respondents comprised students and lecturers from Malaysian premier polytechnics, such as Ibrahim Sultan Polytechnic, Sultan Salahuddin Abdul Aziz Shah Polytechnic and Ungku Omar Polytechnic. However, only 197 final year students and 89 lecturers from bachelor's degree level from four programs (civil engineering department, electric and electronic engineering department and mechanical engineering department as well as the design and visual communication department) were chosen. Analysis of interview session from the experts indicated that three critical technical skill themes are needed for IR4.0: analysing, interpreting and documenting data; understanding and optimising process; and, executing, troubleshooting and maintaining of devices. Findings from the survey concluded that the respondents' level of knowledge and skills to most of the technical competency is still at the average level and requires a lot of improvement. This implies that new technical knowledge should be embedded in the new curriculum on technology for their future knowledge, in order to fit with the need of changes in technology.
\end{abstract}

Keywords: Technical competency, Industrial Revolution 4.0, TVET

\section{Introduction}

Technical and Vocational Education and Training (TVET) initiative is one of the programs that need to be given attention, even though it is often seen as a second-class program offered by higher learning institutions, usually tailored for students who do not excel in their academic studies previously. But today, this notion has changed as TVET is also relevant to all levels of students due to its involvement in education and hands-on job training, which is providing knowledge and skills in their various employments. Basically, the purpose of this program is to prepare students with specific skills for a particular job, thus, making employment easier as they are trained and equipped with the right skills. However, the need for strengthening and transforming this program is crucial in recent years due to the new and more challenging industrial environment, as the world begins to embrace the Fourth Industrial Revolution.

According to the World Economic Forum (2017), most individuals relying on just one set of skill or narrow expertise, are unlikely to sustain in long-term careers in future economy due to the rapid evolution of the job market. These rapid changes are caused by the industrial revolution, known as the Industrial Revolution 4.0 (IR 4.0). It is the industrial and educational policy wake-up call to the working world in the period when digital technologies are increasingly shaping the world. The keyword of IR 4.0 summarises the whole developments derived from digitisation, 
such as cloud technology, big data, robotics, 3-D printing, social media, new interfaces between man and machine as well as the emergence of cyber-physical systems (Ooi, Lee, Tan, Hew \& Hew, 2018).

Recently, the success of new digital technologies has changed the world of work at an unprecedented speed. As stated by Ishak (2016), the IR 4.0 has created a massive uncertainty. As such, some experts believe that this transformation will destroy some jobs and create new posts (Rajnai \& Kocsis, 2017). Against all of the controversial discussions on digital transformation and IR 4.0, all of the debates are more to the call for developing appropriate concepts for professional training and qualification, especially vocational training (Ahmad, 2016). In view of this, the main concept would be based on the question of which competency is needed in the future and how to fulfil the required skill.

Importantly, IR 4.0 presents a new challenge for companies even with decades of experience after the introduction of new automation technology (Pfeiffer, 2015). Currently, many significant factors of the IR 4.0 transformation are influencing global industries to have major impact on jobs ranging from substantial job creation to job displacement and from heightened labour productivity to widening the skills gaps (World Economic Forum, 2016). Consequently, considerable gaps remain on how job profiles will evolve the response to the associated challenges in vocational education and training to ensure that graduates are able to carry out the tasks at specialist level with high quality in the future.

As IR 4.0 takes hold, all workers in every sector including engineers will embrace these digital tools and technologies. As such, the industry needs forward-thinking engineers to make higher-quality products more efficiently, in such a way that can quickly shift consumers' demands, building customers' loyalty and gaining market share. Although, engineers are not only required to redesign processes and operations to accommodate these new advances, most of the impact through IR 4.0 are on them, such as product design in order to increase smart-up manufacturing facilities. In the world of IR 4.0, engineers are required to provide and optimise step-by-step guidance and instructions for multi-machine operators and open to change, possess greater flexibility to adapt to new roles and work environments, including becoming accustomed to continuous interdisciplinary learning (Sackey \& Bester, 2016).

Despite all the challenges in IR4.0, there are lots of opportunities expected for its transformation, such as enormous potential in increasing industrial sector productivity, the establishment of new business model and even contribution to the evolution of jobs and skills to fill the revolution of the technology (Schlaepfer, Koch, \& Merkofer, 2015). Consistent with all discussions in IR 4.0, all these changes require adoption of new teaching technologies and learning process, including digitalising the advance working experience of training institution (Ciolacu, Svasta, Berg, \& Popp, 2017). Additionally, individual competency is critical to provide a spot in the new workplace environment during the transformation.

However, the main issue in the current situation is that contemporary workers and graduates are not competent enough to meet the IR 4.0 requirement. Vinh (2017) study, which was based on Oxford University research, stated that within the next 25 years, all developed nations will face job loss with worrying rate up to $47 \%$. This is because, it would be tough to find people with the right mix of skills who has the combination technical skills, analytical and industry knowledge, including business sense and soft skills to turn data into value for employers (Baker, 2016). Therefore, this study focuses on the need to discover critical technical competency for Malaysian TVET graduates towards future industrial revolution based on three research questions as follows:

i. How is the level of knowledge and skills of polytechnic students and lecturers towards IR 4.0 digital technologies?

ii. What are the technical competencies required by the next industrial revolution?

iii. Is there any difference in the current technical competency with that needed for IR4.0?

\section{The Needs of Skilled Workers in IR4.0}

\subsection{IR4.0 Overview}

In 2011, Germany launched the "Industrie 4.0" initiative as part of its high-tech strategies, introducing the idea of a fully integrated industry (Hofmann \& Rüsch, 2017). In the coming decades, many tasks which are traditionally done by humans will be fully utilised by the machine automatically. This transformation affects the labour market and changes the face of the modern workforce. Currently, IR 4.0 has significantly attracted the attention of the industrial system, either manufacturing side or service system. Nowadays, the focus is more about the successful establishment of intelligent and communicative systems, including machine-to-machine communication and human-machine interaction. As such, it is projected that majority of companies would deal with the establishment of effective data flow management that relies on the acquisition and assessment of data being extracted from the intelligent and distributed system interaction (Wang \& Wang, 2016).

According to Baker (2016), IR 4.0 is the terminology used for representing technologies and concepts of value chain organisations within the modular structure of smart factories of IR 4.0. Judging from the emerging digital operations wave, companies are now revolutionising their businesses with the use of artificial intelligence, robotics, 
cognitive computing and the Industrial Internet of Things (IoT) (Selamat, 2017). Kan et al. (2017) and Ooi, Lee, Tan, Hew and Hew (2018) believed that the transformation to IR 4.0 is mainly based on eight foundational technological advancement. They identified these eight foundations as; adaptive robotics, data analytics and artificial intelligence, simulation, embedded systems, communication and networking such as Industrial Internet, cloud systems and virtualization technologies. These revolutions are supported by underlying technologies, such as cybersecurity, sensors, actuators, RFID, RTLS and mobile application vis a vis another seven design principles, namely real-time data management, interoperability, virtualization, decentralisation, agility, service orientation and integrated business processes (Wang \& Wang, 2016).

\subsection{Implication of IR4.0}

As a developing country, Malaysia aspires to break out from middle-income trap by moving towards technology and knowledge-intensive industry. However, there are several challenges in equipping Malaysian workforces with the necessary skills and broadening the appeal of technical education to a broader segment of the students' population. Flynn, Dance and Schaefer (2017) also stated that higher education is weakly responsive to changes signals and moderately responsive to long-term trends, as such several significant challenges are required in the education sector as highlighted in the following:

i. Identifying technical content to meet the future demands of the labour market

ii. Making education responsive enough to match supply with demand before skills become obsolete

iii. The advent of massive open online courses (MOOCs)

iv. Technical education focusing on 'learning how to learn' from different countries and cultures

In view of the foregoing, it is critical to recognise and evaluate the effects and challenges of IR 4.0, especially the digitalisation of the production processes. As stated by Schlaepfer, Koch and Merkofer (2015), there are several challenges during transformation to IR 4.0, such as information technology security issues, reliability and stability which are needed for critical machine-to-machine communication. Other than these, very short and stable latency maintaining the integrity of production processes, lack of adequate skill-sets to expedite the march towards the IR 4.0 are also considered as challenges that should be faced through the transformation.

Sung (2017) stated that the information technology security risk is the most challenging aspect in implementing IR 4.0, since most of the integration among several entities in IR 4.0 are carried out online, thereby exposing users to security breaches and leaks of data to the cyber theft. Therefore, online security is a crucial issue that should be solved. More so, this IR 4.0 transformation requires massive investments in new technology as Schlaepfer et al. (2015) mentioned that the conversion of IR 4.0 requires the adaptation of existing installations and in some cases, entirely new types of IT infrastructure are needed. This situation demands the industry to develop new communication network from scratch.

\subsection{Polytechnic Graduates Ready Skills}

The Malaysian government has established polytechnics to provide industry-oriented technical education and training to post-secondary school-leavers to enhance the required competencies of the technicians and technical assistants in various fields. Currently, Malaysian polytechnics offers 10 degrees, 9 advanced diplomas, 78 diplomas, 12 prediploma programmes and 7 special skills certificate programmes. As a higher education institution, polytechnics follow the quality assurance and accreditation standards of the Malaysian Qualification Agency (MQA), which subscribes to the Malaysian Qualification Framework (MQF). According to the result of a study conducted by Nordin and Hanapi (2014), there are three factors contributing to un-employability of Malaysian graduates, which are poor graduate attributes, lecturers' competency and education quality.

Employability skill refers to work readiness with the possession of technical attributes, skills and knowledge as required for a job to ensure that employees can be useful in their workplace. This skill could also assist employees in adjusting themselves to various changes of the working environment needs, which could eventually enhance their careers (Normala, Yahya \& Abdul, 2014). According to Rahmat, Ayub and Buntat (2016), employers and industries have voiced out the lack of specific employability skill required from graduate in discharging their duties. Employers said that graduates are not ready to enter and confront the complexities and challenges of the working environment (Marais \& Perkins, 2012).

Based on the Industry Advisory Council (IAC) Meeting held on April 2017 as reported by Kamarudin and Teh, 2017, industrial players voiced out concerned about polytechnic graduates' technical skills, poor soft skills and call for more effective measures of teaching soft skills in the curriculum. At the same time, industries also expect students to equip themselves more on global skills, such as the 21 st century skills vis a vis communication, collaborative, creative, critical thinking, Internet of Things (IoT) and other industry 4.0 requirement skills. According to Hussain (2010) and Pineteh (2012), many unemployed graduates stated that they need additional training programmes to enhance multiple 
skills, such as soft skills, lifelong learning skills, professional ethics and morality, English language skills, ICT skills, career development, interpersonal skills and entrepreneurial skills, in order to be able to fit into available positions offered by the industry. There is also the need of enhancing certain gap in the quality of workers' so as to ensure industrial requirements are met through continuous development of the capabilities of the workforce and contextual implementation (Esa, Selamat, Padil \& Jamaludin, 2014). More so, the total number of unemployed graduates has continued to increase, as such, being one of the major rising issues due to the lack of dominance regarding several skill elements needed by the industry.

\subsection{Technical Competency}

According to Wahba (2010), the definition of competency is the individual's ability to use, apply and demonstrate a group of related awareness, knowledge, skills and attitudes to perform tasks and duties successfully, which are measured through the required standards. This is because, competency will affect the individual's job responsibility and thereby able to perform the job scope, which usually falls into two categories; technical and behavioural.

However, technical competencies such as knowledge, skills and abilities are the requirement to fulfil job tasks, duties and responsibilities, which lead to acceptable performance level at work (UAE Authority, 2016). It describes competencies in technical terms using indicators to help recognising them individually. Ishak (2016) stated that the industry needs the new types of higher skilled worker specializing in specific areas. Another study conducted by Kan et al. (2017) through an in-depth analysis in August 2017 on recruiting activity and digital skills, led to the discovery of a different trend about the opportunities and challenges in building digital workforce. The findings of the analysis finalised that three most demanded skills required by industries are big data, cloud computing and artificial intelligence as at 2017.

\section{Research Methodology}

This quantitative study has implemented survey by distributing a set of questionnaires to selected respondents and to support the finding, researcher has used structured interview with two TVET experts. The interview session was purposely conducted to gain input about the requirement and technical competency needed by TVET graduates to fulfil future required industrial skills, which was further analysed using thematic analysis.

Purposive sampling was also employed in the selection of the respondent, in which the target respondents comprised students and lecturers from Malaysian premier polytechnics, such as Ibrahim Sultan Polytechnic, Sultan Salahuddin Abdul Aziz Shah Polytechnic and Ungku Omar Polytechnic. Premier polytechnics were chosen because they offer degree programmes in related fields. As such, technical competency is a must to produce competitive TVET graduates, either current or future technical skills in the work field. These polytechnics are the benchmark to other polytechnics in upskilling and reskilling their technical competency later on. However, only four programs from three major engineering departments, namely the Civil Engineering Department, Electric and Electronic Engineering Department, Mechanical Engineering Department as well as the Design and Visual Communication Department were chosen based on the IR 4.0 disruption as found in literature review according to the following distributions:

i. Ibrahim Sultan Polytechnic - Bachelor of Visual Communication Design and New Media (with honours)

ii. Sultan Salahuddin Abdul Aziz Shah Polytechnic - Bachelor of Facilities Management (with honours) and Bachelor of Engineering Technology (Medical Electronics) (with honours)

iii. Ungku Omar Polytechnic - Bachelor of Manufacturing Engineering Technology (Supply Chain Management) (with honours) and Bachelor in Civil Engineering Technology (Hons)

However, only final year students from degree programmes were chosen in this study as they already have the most knowledge and skills in their field. The population of this study is 197 final year students and 89 lecturers who are teaching core courses for final year students. This is because the number of the study population is small, as such the researcher decided to use all 286 as the sample for this study.

The questionnaire of this study consists of three sections, where the first section relates to the demographic of the respondent and the second section focuses on awareness and simple knowledge about IR 4.0, while the third section is related to technical competencies of respondents based on demand of skills needed by the industries according to literature reviews. In the second and third section, the items are measured on 5-point Likert scale by using very poor, below average, average, moderate and excellent to measure the items. The questionnaire was tested with the coefficient of reliability (Cronbach's $\alpha$ ) to determine the quality of the question. The Cronbach's $\alpha$ for the awareness and knowledge is 0.705 and technical competency questionnaire gained more than 0.765 which proved that the questionnaire tool is reliable to be used (Weiner, 2007). 


\section{Result and Discussion}

\subsection{Respondents' Demographic}

The questionnaires were distributed to the respondents where 193 respondents answered the survey, representing a response rate of $67.48 \%$. Table 1 summarises the respondents' academic background, which shows that $29.5 \%$ of respondents are from IT background while $70.5 \%$ of them are from engineering. Table 2 shows that the majority of respondents do not have any industry experience, in which only $4.7 \%$ respondents have more than 5 years' experience in the industry.

Table 1: Summary of Respondents’ Academic Background

\begin{tabular}{lcc}
\hline $\begin{array}{l}\text { Respondents' Academic } \\
\text { Background }\end{array}$ & Frequency & Per Cent \\
\hline IT-Based & 57 & 29.5 \\
Engineering & 136 & 70.5 \\
Total & $\mathbf{1 9 3}$ & $\mathbf{1 0 0}$ \\
\hline
\end{tabular}

Table 2: Summary of Respondents' Industry Experience

\begin{tabular}{lcc}
\hline Industry Experience & Frequency & Per cent \\
\hline More than five years & 9 & 4.7 \\
$1-5$ years & 11 & 5.7 \\
Below than five years & 38 & 19.7 \\
No industry experience & 135 & 69.9 \\
\hline
\end{tabular}

\subsection{How is the level of knowledge and skills of polytechnic's students and lecturers in IR 4.0 digital technologies?}

Consequently, the IR4.0 should be implemented in an interdisciplinary manner with close cooperation with other key areas using different technologies drivers. According to Rüßmann et al. (2015), there are nine pillars of the technological advancement in IR 4.0. These are big data, autonomous robots, simulation, universal system integration, industrial IoT, cyber security, cloud computing, additive manufacturing and augmented reality. Based on the analysis of the questionnaire, the majority of the respondents have average level of expertise in big data $(\mathrm{M}=3.09, \mathrm{SD}=0.620)$, artificial intelligence $(\mathrm{M}=3.07, \mathrm{SD}=0.541)$, developing smart sensor system $(\mathrm{M}=3.02 \mathrm{SD}=4.810)$ with moderate knowledge on the Internet of Things (IoT) $(\mathrm{M}=3.58, \mathrm{SD}=0.512)$, mobile application development $(\mathrm{M}=3.35, \mathrm{SD}=0.660)$ and networking $(\mathrm{M}=3.33, \mathrm{SD}=0.654)$. The study results also showed that up to $75 \%$ of the respondents have low level of skills in cloud computing $(\mathrm{M}=2.80, \mathrm{SD}=0.635)$, troubleshooting $(\mathrm{M}=2.55, \mathrm{SD}=0.441)$ and cyber security $(\mathrm{M}=2.31$, $\mathrm{SD}=0.570$ ). Meanwhile, up to $89 \%$ of the respondents have knowledge and skills in programming language and most of them are able to do programming with $C++$, Java and $S Q L$ programming language as offered in their curriculum. Only $2 \%$ of the respondents can use other programming languages including Perl and Phyton. None of the respondents are able to use Ruby language and familiar with the Node.Js environment.

Oracle (2016) demonstrated that IR 4.0 does not only focus and embrace big data, advanced analytics, IoT, digital modelling, additive manufacturing, computer and integrated manufacturing, but also, the combination of all of them so as to make a whole transformation much greater than the sum of its parts.

\subsection{What are the technical competencies required by the next industrial revolution?}

Competency is referred as most of the collection of knowledge, skills, ability and other characteristics needed for effective performance in the job areas (Dworschak \& Zaiser, 2014).

After comparing and ranking them according to different categories, three themes and patterns were identified according to how significant they are to the research questions based on the structured interview session with two TVET expert. The findings of crucial future technical competencies needed by the industries are as stated in Table 3 below: 
Table 3: Future Technical Competencies

\begin{tabular}{ll}
\hline Technical Competencies & Description \\
\hline $\begin{array}{l}\text { Analysing, interpreting and } \\
\text { documenting data }\end{array}$ & $\begin{array}{l}\text { Consist of skills in connecting data via databases, } \\
\text { maintenance, servicing with digital instruments, data } \\
\text { analysis, interpretation of data, making use of knowledge } \\
\text { and documentation systems. }\end{array}$ \\
$\begin{array}{l}\text { Understanding and optimising } \\
\text { process }\end{array}$ & $\begin{array}{l}\text { Include all the skills in coherence the network through the } \\
\text { integration and real-time synchronisation of processes } \\
\text { along the value-added method, application of the intelligent } \\
\text { device and the availability of knowledge. }\end{array}$ \\
$\begin{array}{l}\text { Execute troubleshooting and } \\
\text { maintaining devices }\end{array}$ & $\begin{array}{l}\text { This skill are more about troubleshooting in complex, } \\
\text { networked fault repair, reading and interpreting of } \\
\text { operational data, troubleshooting in mechanic components } \\
\text { and sensor technology as well as signal processing. }\end{array}$ \\
\hline
\end{tabular}

This finding is in line with those obtained by Pension et al. (2017), which also listed the final set of technical skills for IR 4.0, including analysis, modelling, programming and use of collaborative robots, use of additive manufacturing technologies, simulation, design and building of digital supply networks, big data management as well as the implementation of IT architectures, platforms and component orientation towards IR 4.0.

\subsection{Is there any difference in the current technical competencies or any technical competency needed for IR4.0?}

Based on the empirical study through previous literatures and the findings from the interview session, it is clearly apparent that there is a difference in current technical skills compared to the IR 4.0 skills requirement. On the other hand, training and continuous professional development represent other fundamental critical factors for achieving the IR 4.0 objectives, as they will significantly transform job and skill profiles of the workers (Barbara, Gabriele, Stefano \& Domenico, 2017). This is why Tan and Tang (2016) suggested that Malaysia needs to revamp its curriculum in higher education, soft skills and English proficiency, tighten coordination between government, industry and education institutions while expanding the sources of skilled workers in order to reduce the skill gaps.

\section{Conclusion}

The results of this study concluded that the respondents' level of knowledge and skills of most of the crucial elements and components needed for IR 4.0 technology advancement is still at the average level which requires lots of improvement. It shows that, forcing to realise what will happen in the future is not enough without doing something to it, at least reducing the skill gap between job demand skills and the current skills. As there are differences in current technical competencies with technical competency needed for IR 4.0, it is recommended that TVET institutions should start restructuring the learning process of learning the software, getting to know network structures so as to master bigdata technologies. Additionally, they should learn to work with various data formats, understand and master the processes, intensively cooperate and communicate, as well as initiating more innovations.

In other situations, introduction to the other trending programming language and IR 4.0 technologies should also be considered so as to ensure TVET graduates can have their competing chance in getting job after finishing their study. New technical knowledge should be embedded in the new curriculum on technology for their future knowledge, in order to fit with the need of changes in technology. Since this study was done only to identify technical competencies among polytechnic students and lecturer, further in-depth and detailed study is recommended to be carried out to discover other competencies needed to fit the requirement of future industrial revolution job skills, which can develop the framework of technical competencies.

\section{References}

Abdullah, A. H. (2011). The Development of Human Resource Practitioner Competency Model Perceived by Malaysian Human Resource Practitioners and Consultants: A Structural Equation Modelling (SEM) Approach. International Journal of Business and Management, 6(11). doi: 10.5539/ijbm. v6n11p240

Ahmad, Z. (2016). Education 2030 Launch and Symposium. Malaysia Ministry of Education, (August). Retrieved from https:/www.moe.gov.my/images/Terbitan/Rujukan-Akademik/Presentation-Education-2030-Launch-Symposium-23rdAugust-2016-Hotel-Istana-Ballroom-Kuala-Lumpur/Zanariah-Hj-Ahmad/Zanariah Hj. Ahmad.pdf 
Baker, K. (2016). The digital revolution, 28.

Ciolacu, M., Svasta, P. M., Berg, W., \& Popp, H. (2017). Education 4.0 for Tall Thin Engineer in a Data Driven Society. 2017 IEEE 23Rd International Symposium for Design and Technology in Electronic Packaging (Siitme), 438443. https://doi.org/10.1109/SIITME.2017.8259942

Ishak, H. (2016). Industrial Revolution 4.0 in Malaysia? "Fostering Research and Malaysian Aerospace Industry " Factory of The Future. MyForesight, 2012(031478), 44.

Ooi, K. B., Lee, V. H., Tan, G. W. H., Hew, T. S., \& Hew, J. J. (2018). Cloud computing in manufacturing: The next industrial revolution in Malaysia? Expert Systems with Applications, 93, 376-394. https://doi.org/10.1016/j.eswa.2017.10.009

Oracle. (2016). The Manufacturer UK Readiness Report. The Manufacturer, 16. Retrieved from https://www.oracle.com/webfolder/s/delivery_production/docs/FY16h1/doc19/Industry-Report.pdf

Pfeiffer, S. (2015). Effects of Industry 4.0 on vocational education and training, (November/2015), 51. Retrieved from http://epub.oeaw.ac.at/ita/ita-manuscript/ita_15_04.pdf

Pinzone, M., Fantini, P., Perini, S., Garavaglia, S., Taisch, M., \& Miragliotta, G. (2017). Jobs and Skills in Industry 4.0: An Exploratory Research (pp. 282-288). https://doi.org/10.1007/978-3-319-66923-6_33

Rajnai, Z., \& Kocsis, I. (2017). Labor market risks of industry 4.0, digitization, robots and AI. SISY 2017 - IEEE 15th International Symposium on Intelligent Systems and Informatics, Proceedings, 343-346. https://doi.org/10.1109/SISY.2017.8080580

Sackey, S. M., \& Bester, \& A. (2016). Industrial Engineering Curriculum In Industry 4.0 In A South African Context. South African Journal of Industrial Engineering, 27(4), 101-114. https://doi.org/10.7166/27-4-1579

Schlaepfer, R. C., Koch, M., \& Merkofer, P. (2015). Industry 4.0. Challenges and Solutions for the Digital Transformation and Use of Exponential Technologies. Deloitte, 1-30.

Tan, K. S., \& Tang, J. T. H. (2016). New Skills at Work: Managing Skills Challenges in ASEAN-5. Retrieved from http:/ink.library.smu.edu.sg/cgi/viewcontent.cgi?article=2891\&context=soe_research

Weiner, J. (2007). Measurement: Reliability and Validity Measures. Johns Hopkins University. Retrieved from http://ocw.jhsph.edu/courses/hsre/PDFs/HSRE_lect7_weiner.pdf

World Economic Forum. (2016). The Future of Jobs Employment, Skills and Workforce Strategy for the Fourth Industrial Revolution. Growth Strategies, (january), 2-3. https://doi.org/10.1177/1946756712473437

World Economic Forum. (2017). Realizing Human Potential in the Fourth Industrial Revolution An Agenda for Leaders to Shape the Future of Education, Gender and Work, (January), 35. unesco.org/eforum/CompetenceStandardsforTVET.pdf

World Economic Forum (2016). Human Capital Outlook Association of Southeast Asian Nations (ASEAN). Regional Community Briefing, Kuala Lumpur, 1st -2nd June 2016.

Zain M. I. (2017). The Collaborative Instructional Design System (CIDS): Visualizing the 21st Century Learning. Universal Journal of Educational Research 5(12): 2259-2266, 2017.

Zawra, L. M., Mansour, H. A., Eldin, A. T., \& Messiha, N. W. (2018). Proceedings of the International Conference on Advanced Intelligent Systems and Informatics 2017, 639. https://doi.org/10.1007/978-3-319-64861-3

Zezulka, F., Marcon, P., Vesely, I., \& Sajdl, O. (2016). Industry 4.0 - An Introduction in the phenomenon. IFACPapersOnLine, 49(25), 8-12. https://doi.org/10.1016/j.ifacol.2016.12.002

Zhou, K., Liu, T., \& Zhou, L. (2016). Industry 4.0: Towards future industrial opportunities and challenges. 2015 12th International Conference on Fuzzy Systems and Knowledge Discovery, FSKD 2015, 2147-2152. https://doi.org/10.1109/FSKD.2015.7382284 